\title{
Synthesis and Superconducting Properties of $\mathrm{HgBa}_{2} \mathrm{Ca}_{2} \mathrm{Cu}_{3} \mathrm{O}_{8+x}$
}

\author{
Sergey Lee, ${ }^{a, b}$ Mi-Ock Mun, ${ }^{a}$ Myoung-Kwang Bae ${ }^{a}$ and Sung-lk Lee, ${ }^{a, c}$ \\ ${ }^{a}$ Department of Physics, Pohang University of Science and Technology, Pohang, 790-784, Korea \\ ${ }^{b}$ Department of Chemistry, Moscow State University, Moscow 119899, Russia \\ ${ }^{c}$ Physics Division, Research Institute of Industrial Science and Technology, Pohang, 790-600, Korea
}

The influence of precursor composition, nominal mercury vapour pressure $\left(P_{\mathrm{Hg}}\right)$ and reaction temperature $(t)$ on the formation of $\mathrm{HgBa}_{2} \mathrm{Ca}_{2} \mathrm{Cu}_{3} \mathrm{O}_{8+x}$ have been studied. By reducing the empty space inside the quartz tube, we could increase $P_{\mathrm{Hg}}$ higher than 200 atm and obtain samples containing only $\mathrm{HgBa}_{2} \mathrm{Ca}_{2} \mathrm{Cu}_{3} \mathrm{O}_{8+x}$ as the superconducting phase, with $T_{\mathrm{c}}$ (onset) $=134 \mathrm{~K}$ and $T_{\mathrm{c}}$ (zero) $=131 \mathrm{~K}$.

Superconductivity above $130 \mathrm{~K}$ for $\mathrm{Hg}$-containing cuprates was discovered recently by Shilling et al. ${ }^{1}$ The $\mathrm{HgBa}_{2} \mathrm{Ca}_{2} \mathrm{Cu}_{3} \mathrm{O}_{8+x}(\mathrm{Hg}-1223)$ phase was known to be a response to $130 \mathrm{~K}$ superconductivity, but production of this single phase has not yet been successful. Several different methods have been suggested to prepare high-fractional Hg-1223 samples.

First, Antipov et al. ${ }^{2}$ applied high pressure $(50 \mathrm{kbar})$ at $950{ }^{\circ} \mathrm{C}$ in a belt-type apparatus. $\mathrm{Hg}-1223$ was present as the main phase in the sample; however, some $\mathrm{HgBa}_{2} \mathrm{Ca}_{1} \mathrm{Cu}_{2} \mathrm{O}_{6+x}$ ( $\mathrm{Hg}-1212)$ and other impurity phases were also detected. Moreover, the process requires complex equipment for sintering under high pressure and temperature. Compared with this, the synthesis of $\mathrm{Hg}-1233$ in an evacuated quartz ampoule has several benefits owing to its simplicity. ${ }^{3,4}$ The most promising modification of this method was reported by Meng et $a .^{5}$ The authors used the reactant pellet $(\mathrm{R})$ with nominal composition $\mathrm{HgBa}_{2} \mathrm{Ca}_{2} \mathrm{Cu}_{3} \mathrm{O}_{y}$ (not a phase) as a composite $\mathrm{Hg}$ source for the precursor $(\mathrm{P}), \mathrm{Ba}_{2} \mathrm{Ca}_{2} \mathrm{Cu}_{3} \mathrm{O}_{y}$, during heat treatment inside a quartz ampoule. Samples containing about $65 \% \mathrm{Hg}-1223$ were obtained within the temperature range $850-860^{\circ} \mathrm{C}$. However, the strong sensitivity of the phase composition to $\mathrm{P}: \mathbf{R}$ ratio and possible interaction between the quartz and samples at high temperatures are the most serious problems of this method.

Here, we report a simple method for fabricating a highquality superconducting sample with $\mathrm{Hg}-1223$ as the main phase. For this sample, we tried every method to reduce the empty space inside the quartz tube, and increased $P_{\mathrm{Hg}}$ to
$>200 \mathrm{~atm}$, much higher than in the previously published sample used for the high-pressure study. ${ }^{6}$

The samples were synthesized by the following procedure. The precursors with $\mathrm{Ba}: \mathrm{Ca}: \mathrm{Cu}$ cation ratios of $2: 1: 2$, $2: 1.5: 2.5$ and $2: 2: 3$ were prepared by mixing appropriate amounts of the nitrates $\mathrm{Ba}\left(\mathrm{NO}_{3}\right)_{2}, \mathrm{Ca}\left(\mathrm{NO}_{3}\right)_{2} \cdot 4 \mathrm{H}_{2} \mathrm{O}$ and $\mathrm{Cu}\left(\mathrm{NO}_{3}\right)_{2} \cdot 2.5 \mathrm{H}_{2} \mathrm{O}$. The mixture of reagents was heated to 650 and $700^{\circ} \mathrm{C}$ in air for $20 \mathrm{~h}$ with intermediate grinding. The resulting powder was then compressed into a pellet and heated in an oxygen atmosphere for $60 \mathrm{~h}$ at $900^{\circ} \mathrm{C}$ with two intermediate grindings. A stoichiometric amount of $\mathrm{HgO}$ (yellow) was added to the precursor and mixed in a glove box under a nitrogen atmosphere. Pellets of nominal composition $\mathrm{HgBa}_{2} \mathrm{Ca}_{1} \mathrm{Cu}_{2} \mathrm{O}_{y}, \mathrm{HgBa}_{2} \mathrm{Ca}_{1.5} \mathrm{Cu}_{2.5} \mathrm{O}_{y}$ and $\mathrm{HgBa}_{2} \mathrm{Ca}_{2} \mathrm{Cu}_{3} \mathrm{O}_{y}$ were placed inside an alumina tube and then inside a thickwalled quartz tube. The empty space inside the tube was reduced by packing it with quartz rods of different lengths. The volume of ampoule and amount of sample were adjusted to obtain the nominal 'mercury vapour pressure' during heat treatment. Here, 'mercury vapour pressure' means the calculated pressure inside the ampoule assuming that the $\mathrm{HgO}$ totally decomposes and all of the $\mathrm{Hg}$ remains unreacted. The value of this parameter for our experiments varied over the $80-300 \mathrm{~atm}$ range. The evacuated tube was sealed and placed in a steel container. The samples were heated at $160 \mathrm{~K} \mathrm{~h}^{-1}$ to a temperature between 800 and $950{ }^{\circ} \mathrm{C}$, kept at this temperature for $5 \mathrm{~h}$ and then cooled at $80 \mathrm{~K} \mathrm{~h}^{-1}$ to room temperature. The oxygenation of the samples was carried out in flowing oxygen at $300^{\circ} \mathrm{C}$ for $20 \mathrm{~h}$.

Table 1 Estimated phase fraction according to XRD analysis in samples prepared under different conditions

\begin{tabular}{|c|c|c|c|c|c|c|c|}
\hline \multirow{2}{*}{$\begin{array}{l}\text { sample } \\
\text { number }\end{array}$} & \multirow{2}{*}{$\begin{array}{c}p^{a} / \\
\mathrm{g} \mathrm{cm}^{-3}\end{array}$} & \multirow[b]{2}{*}{$t /{ }^{\circ} \mathrm{C}$} & \multicolumn{5}{|c|}{ estimated volume fraction $(\%)$} \\
\hline & & & $\mathrm{Hg}-1223$ & $\mathrm{Hg}-1212$ & $\mathrm{Hg}-1201$ & $\mathrm{CaHgO}_{2}$ & $\mathrm{BaCuO}_{2}$ \\
\hline \multicolumn{8}{|c|}{ ref. 5} \\
\hline Hg-91 & 0.19 & 800 & - & - & 30 & 40 & 30 \\
\hline $\mathrm{Hg}-94$ & 0.30 & 800 & - & 10 & 50 & 20 & 20 \\
\hline $\mathrm{Hg}-95$ & 0.33 & 800 & - & 50 & 10 & 20 & 20 \\
\hline $\mathrm{Hg}-65$ & 1.06 & 800 & - & 60 & - & 25 & 15 \\
\hline \multicolumn{8}{|c|}{ our results } \\
\hline N1 & 1.02 & 800 & - & 40 & - & 25 & 35 \\
\hline N2 & 1.25 & 800 & 25 & 30 & - & - & 45 \\
\hline N3 & 2.00 & 800 & 25 & 35 & - & - & 40 \\
\hline N4 & 2.00 & 830 & 35 & 20 & - & - & 45 \\
\hline N5 & 2.00 & 850 & 45 & 15 & - & - & 50 \\
\hline N6 & 2.00 & 900 & 55 & - & - & - & 45 \\
\hline N7 & 2.50 & 900 & 70 & - & - & - & 30 \\
\hline N8 & 2.50 & 930 & 50 & 20 & - & - & 30 \\
\hline
\end{tabular}

${ }^{a} p=$ reactant mass per unit volume. 


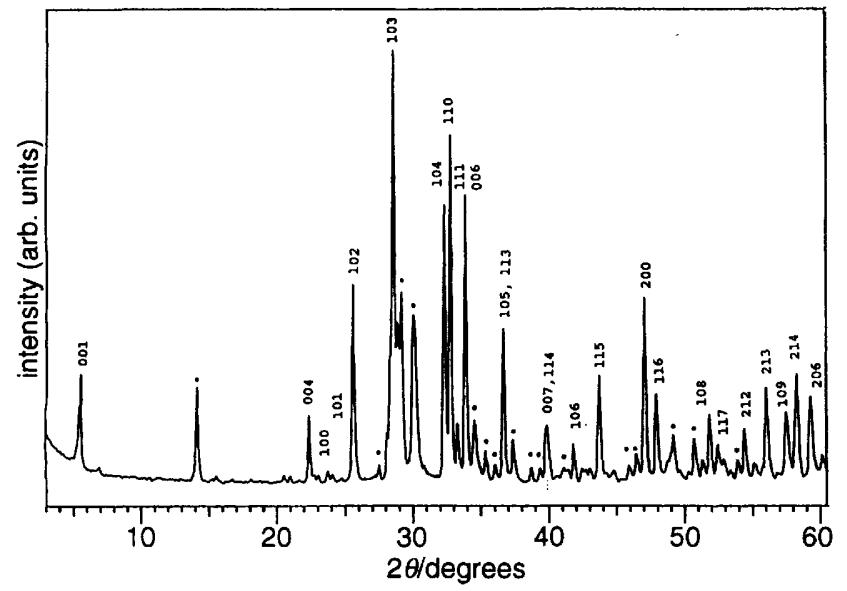

Fig. 1 X-Ray diffraction pattern for sample N7. Indexed XRD intensities correspond to $\mathrm{Hg}-1223$. Impurity phases are marked by

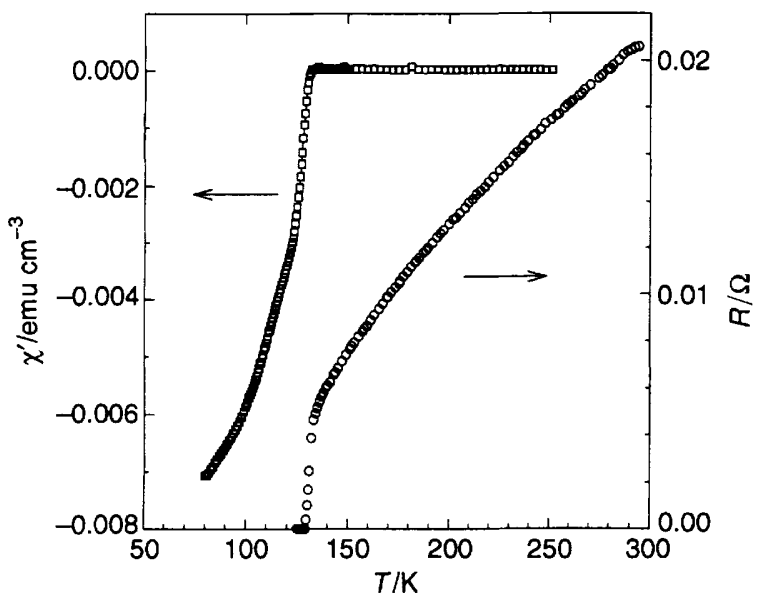

Fig. 2 Resistance and ac magnetic susceptibility vs. $T$ for sample N7 with $\mathrm{Hg}-1223$ as the major superconducting phase. $T_{\mathrm{c}}$ (onset) $=134 \mathrm{~K}$ and $T_{\mathrm{c}}$ (zero) $=131 \mathrm{~K}$

The results of XRD analysis for our samples in comparison with ref. 5 are summarized in Table 1 . We used the ratio of the intensities of the (103) line for $\mathrm{Hg}-1212$ and $\mathrm{Hg}-1223$, to estimate the approximate amounts of these phases. The (442) and (012) lines were chosen for the main impurity phases of $\mathrm{BaCuO}_{2}$ and $\mathrm{CaHgO}_{2}$, respectively.

For a pellet composition of $\mathrm{HgBa}_{2} \mathrm{Ca}_{1} \mathrm{Cu}_{2} \mathrm{O}_{y}$ and a reaction temperature of $800^{\circ} \mathrm{C}$, Meng et al..$^{5}$ found that at low $\mathrm{Hg}$ vapour pressure, associated with a low reactant concentration in the ampoule $(p)$, only $\mathrm{Hg}-1201$ was formed, together with a larger amount of $\mathrm{CaHgO}_{2}$ and $\mathrm{BaCuO}_{2}$. The fraction of
$\mathrm{Hg}-1212$ increased to $60 \%$ by increasing $p$ to $1.06 \mathrm{~g} \mathrm{~cm}^{-3}$. However, the Hg-1223 phase could not be found in their experiments. This is also confirmed in our sample N1. However, by further increasing $p$ up to $1.25 \mathrm{~g} \mathrm{~cm}^{-3}$ we successfully made sample $\mathrm{N} 2$ containing $\mathrm{Hg}-1223$ phase together with $\mathrm{Hg}-1212$ and $\mathrm{BaCuO}_{2}$. We could not detect $\mathrm{CaHgO}_{2}$ in sample $\mathrm{N} 2$ with high $p$, while in sample N1 with low $p$ the amount of this phase was quite high. The data were confirmed by ac susceptibility measurements, which indicated the presence of two phases, $\mathrm{Hg}-1223$ and $\mathrm{Hg}-1212$, with superconducting transitions at 130 and $126 \mathrm{~K}$, respectively, in an oxygenated bulk sample.

The effect of temperature on the formation of $\mathrm{Hg}-1212$ and $\mathrm{Hg}-1223$ in samples with a nominal chemical composition of $\mathrm{HgBa}_{2} \mathrm{Ca}_{1.5} \mathrm{Cu}_{2.50}$ was studied. Four different temperatures, $800,830,855$ and $900^{\circ} \mathrm{C}$, were chosen to study the temperature effect (samples N3, N4, N5 and N6, respectively). $p$ was kept constant at $2.0 \mathrm{~g} \mathrm{~cm}^{-3}$ in all the experiments. It is important that $\mathrm{Hg}-1212$, which was reported ${ }^{5}$ to be unstable above $820^{\circ} \mathrm{C}$, still exists in the sample at 830 and $855^{\circ} \mathrm{C}$ and disappears only at $900^{\circ} \mathrm{C}$.

The best samples were obtained by using a stoichiometric $\mathrm{HgBa}_{2} \mathrm{Ca}_{2} \mathrm{Cu}_{3} \mathrm{O}_{y}$ composition at $900^{\circ} \mathrm{C}$ (sample N7). It contained $\mathrm{Hg}-1223$ as the main superconducting phase with no traces of $\mathrm{Hg}-1212$ (Fig. 1). At $930^{\circ} \mathrm{C}$ (sample $\mathrm{N} 8$ ) the total amount of superconducting phases remained constant, but Hg-1212 was present as a second superconducting phase. A further increase of temperature up to $950^{\circ} \mathrm{C}$ led to a rupture of the quartz ampoule in the present experiment. A possible reason for such a rupture is the decomposition of the $\mathrm{Hg}$-containing phases and an increase in the mercury vapour pressure inside the ampoule. So, according to our data, $\mathrm{Hg}-1223$ starts to decompose above $900^{\circ} \mathrm{C}$ and the optimum temperature for $\mathrm{Hg}-1223$ formation is about $900^{\circ} \mathrm{C}$. However, the optimum temperature may change for another $p$ value. The resistance and ac susceptibility measurement data for sample N7 (Fig. 2) confirmed its high quality.

\section{References}

1 A. Schilling, M. Cantoni, J. D. Guo and H. R. Ott, Nature (London), 1993, 363, 56

2 E. V. Antipov, S. M. Loureiro, C. Chaillout, J. J. Capponi, J. L. Tholence, S. N. Putilin and M. Marezio, Physica C, 1993, 215, 1 .

3 A. Tokiwa-Yamamoto, K. Isawa, M. Itoh, S. Adachi and H. Yamauchi, Physica C, 1993, 216, 250.

4 J. L. Wagner, P. G. Radaelli, D. G. Hinks, J. D. Jorgensen, I. F. Mitchell, B. Dabrowski, G. S. Knapp and M. A. Beno, Physica $C, 1993,10,447$.

5 R. L. Meng, L. Beauvais, X. N. Zang, Z. J. Huang, Y. Y. Sun, Y. Y. Xue and C. W. Chu, Physica C, 1993, 216, 21.

6 C. W. Chu, L. Gao, F. Chen, Z. J. Huang, R. L. Meng and Y. Y. Xue, Nature (London) 1993, 365, 323. 